\title{
Modifications of the Omega ratio for decision making under uncertainty
}

\author{
Helena Gaspars-Wieloch ${ }^{1, *}$ \\ ${ }^{1}$ Faculty of Informatics and Electronic Economy, Poznañ University of Economics \\ Al. Niepodleglosci 10, 61-875 Poznań, Poland \\ E-mail: 〈helena.gaspars@ue.poznan.pl〉
}

\begin{abstract}
The Omega ratio ( $\Omega$-ratio) was proposed by Shadwick and Keating in 2002 as a performance measure applied to rankings of assets, portfolios or funds. It involves partitioning returns into loss and gain below and above a given threshold. The original version was designed for decision making under risk (probabilities completely known), but recent research has shown that this measure can be adapted to decision making under partial information (likelihood known incompletely). Our contribution will be to use the concept of the Omega ratio in decision making under uncertainty (DMUU) which occurs when the decision maker (DM) chooses the appropriate alternative on the basis of certain scenarios for which probabilities are not known at all. The goal of this article is to adjust the $\Omega$-ratio to DMUU so that it takes into consideration the DM's attitude towards risk and the distribution of all payoffs connected with particular decisions. The $\Omega$-ratio is combined with a hybrid of Hurwicz and Bayes rules proposed by the author in another paper. The significant advantage of the new measure, $\Omega(\mathrm{H}+\mathrm{B})$ ratio, is the possibility to compare alternatives (strategies, projects) when the likelihood of particular scenarios is not known or when the DM does not intend to use the available data.
\end{abstract}

Keywords: Omega ratio, hybrid of the Hurwicz and Bayes decision rules, decision making under uncertainty, scenario planning, optimal pure strategy, reference point, Omega $(\mathrm{H}+\mathrm{B})$ rule

Received: September 24, 2014; accepted: March 3, 2015; available online: March 30, 2015

DOI: $10.17535 /$ crorr.2015.0015

\section{Introduction}

The Omega ratio ( $\Omega$-ratio) was created by Shadwick and Keating $[47,48]$. It is a performance measure of an investment asset, portfolio or strategy. It involves partitioning returns into loss and gain above and below a given threshold (point of reference). The $\Omega$-ratio is then the ratio of the probability of having a gain and the probability of having a loss. The original Omega was developed for

${ }^{*}$ Corresponding author. 
decision making under risk (DMUR), that is, for decision problems where the probabilities of particular scenarios (events, states of nature) are known [51, 52].

The literature reveals that a considerable number of extensions of the $\Omega$ ratio have been suggested recently $[1,28,29,31,38]$. Some of them $[29,38]$ are devoted to decision making under partial (incomplete, imprecise) information (DMPI), which is characterized by probability distributions that are incompletely known, see e.g. [5, 22, 32, 34, 35, 56].

In this contribution, we examine the possibility of using the concept of the Omega ratio in decision making under uncertainty (DMUU) which occurs when future factors are neither deterministic (decision making under certainty, DMUC) nor probabilistic (DMUR or DMPI) at the time of the decision. Within the framework of DMUU the decision maker (DM) has to choose the appropriate alternative (decision, project, strategy) on the basis of some scenarios which probabilities are not known $[6,21,33,45,51,52,54]$. This is the so-called "complete uncertainty" or "uncertainty without probabilities" [43]. The goal of this article is to adjust the Omega ratio to DMUU so that the modified measure takes into consideration DM's preferences, i.e. the DM's attitude towards risk understood as the possibility that some bad circumstances might happen (high losses or low gains). The paper is organized as follows: Section 2.1 deals with the main features of DMUU and scenario planning; Section 2.2 briefly describes the $\Omega$-ratio and its extensions; Section 2.3 is devoted to presenting a hybrid of the Hurwicz and Bayes rules $(\mathrm{H}+\mathrm{B}$ rule) for DMUU which was proposed by the author in [13]; Section 3 demonstrates how the Omega ratio can be combined with the $\mathrm{H}+\mathrm{B}$ rule; Section 4 presents an illustrative example. Conclusions are gathered and presented in Section 5.

\section{Theoretical background}

\subsection{Decision making under uncertainty with scenario planning}

We will assume that the term "uncertainty" means "external uncertainty", i.e. uncertainty arising when the consequences of an action are unknown because they depend on future events (which are beyond the DM's control). The result of the choice made under uncertainty with scenario planning depends on two factors: which decision will be selected and which scenario will occur [42]. The DMUU can be presented by means of a payoff matrix where $m$ (the number of rows) denotes the number of mutually exclusive scenarios $\left(S_{1}, S_{2}, \ldots S_{i}, \ldots S_{m}\right), n$ (the number of columns) stands for the number of decisions $\left(D_{1}, D_{2}, \ldots, D_{j}, \ldots\right.$, $\left.D_{n}\right)$ and $a_{i j}$ is the profit connected with scenario $S_{i}$ and alternative $D_{j}$. We assume in this paper that the distribution of payoffs related to a given decision is discrete and that the set of those profits can be a multiset (or a bag). The contribution concerns only one-criterion decision problems and optimal pure 
strategy searching. A pure strategy is a solution assuming that the DM chooses and completely executes only one alternative. Meanwhile the mixed strategy (mixed acts, mixed actions) allows the DM to select and perform a weighted combination of several accessible alternatives [14, 39, 43, 51].

There are many classical decision rules designed for DMUU, such as the Wald's criterion [55], the maximax criterion, presented for example in [40], the Hurwicz's criterion [25, 26], the Savage's criterion [45], the maximin joy criterion $[23,24]$, the Bayes' (Laplace's) criterion (presented e.g. in [44]). The literature also offers various extensions or hybrids of those methods, see e.g. [2, 3, 4, 7, 8, $9,10,11,12,13,15,16,17,18,19,20,27,36,41,46,53]$. Nevertheless, the majority of the extended rules refer to the probability calculus (for instance, expected profit maximization, expected utility maximization, subjective expected utility, maximin expected utility, $\alpha$-maximin expected utility, restricted Bayes/Hurwicz, prospect theory, cumulative prospect theory, Choquet expected utility), which is rather characteristic of DMUR. Let us recall that according to the Knight's definition, the uncertainty occurs when we do not know (i.e. we cannot measure) the probabilities of particular scenarios ("when the uncertainty can be measured it is called"risk" [33]).

\subsection{The Omega ratio}

The Omega ratio serves to evaluate the performance of an investment, especially an investment fund. It is used to make rankings of portfolios, funds and assets. It can be applied to portfolio optimization models $[1,30,37]$ and robust optimization models [29].

In recent years, the Omega ratio has become a dominant performance measure within the downside risk framework, in part due to its relative simplicity and its complete non-reliance on any assumptions about the distribution of the empirical returns or the shape of the utility function. The Omega ratio is calculated according to Equation (1):

$$
\Omega(r)=\frac{\int_{r}^{b}(1-F(x)) d x}{\int_{a}^{r} F(x) d x}
$$

where $[a, b]$ is the interval of returns, $F(x)$ is the cumulative distribution function and $r$ denotes the threshold or point of reference defining the gain versus the loss. Other formulas for the original Omega ratio are presented in $[1,28]$. The higher the ratio the better. Omega takes the value 1 when $r$ is the mean outcome. Note that a point of reference is also applied for instance by Tversky and Kahneman [27, 53]. 
In contrast to the Sharpe ratio [48, 49], where only the first two moments have an influence on the risk measure, the $\Omega$-ratio enables taking into account all moments of the distribution. Omega was developed "to overcome the inadequacy of many traditional performance measures applied to investments that do not have normally distributed return distributions" [47]. When calculating Omega, no assumptions about risk preferences or utility are necessary though they may be accommodated.

The standard formulation of the Omega ratio and its first extensions (e.g. Sharpe-Omega [31], Kappa [28], Omega-H [1]) require perfect information for the probability distribution of the asset returns, which is the case of DMUR. However, in further research, the problem arising from the probability distribution only partially known (DMPI) was also investigated (see the $\max \Omega$ min optimization rule [38] and the robust variant of the conventional Omega ratio, i.e. the worst-case Omega ratio [29]).

As is evident, the numerator (or the denominator) of the above fraction (Equation 1) may equal zero when all outcomes connected with a decision are lower (or higher) than the point of reference. This leads to a situation where the Omega ratios of particular alternatives are not comparable. That is why certain rules have been proposed to overcome this impediment [38]. They consist of dividing all decisions into three groups: (A) alternatives with gains and losses (both the numerator and the denominator of the $\Omega$ ratio are positive), (B) alternatives with no losses, (C) alternatives with no gains. The division is followed by using the Omega fraction only for decisions containing gains and losses. For the remaining alternatives, only the positive numerator or denominator is taken into account. After making the best decision in each group separately, an additional criterion (the difference between total gains and losses) is introduced to compare the "winners" of particular groups and select the final decision. The rules suggested in [38] also enable avoiding the occurrence of more than one optimal alternative.

\subsection{A hybrid of the Hurwicz and Bayes rules $(\mathrm{H}+\mathrm{B}$ rule)}

As was mentioned in Section 1, a hybrid of the Hurwicz and Bayes rules has been already described in [13]. In the opinion of the author, combining this procedure and the original Omega ratio provides a new tool in decision making under uncertainty. Hence, let us briefly analyze the essence of the $\mathrm{H}+\mathrm{B}$ rule.

This method, thanks to parameter $\alpha$, takes into account the DM's preferences, i.e. the DM's attitude towards risk. Symbol $\alpha$ denotes the coefficient of pessimism, which fulfills the following condition: $\alpha \in[0,1]$. It is close to 0 for extreme optimists, i.e. adventurous decision makers (risk-prone behavior), and it tends towards 1 for radical pessimists, i.e. cautious decision makers (risk-averse behavior). This coefficient is not a measure of probability - 
it is just a subjective parameter presenting someone's behavior. Of course, $\beta$ stands for the coefficient of optimism and $\alpha+\beta=1$. The original version of the Hurwicz rule also applies $\alpha$ and usually leads to sensible results, but in some cases this procedure provides answers contradictory to the logic and not reflecting the decision maker's preferences. Such a phenomenon is due to the fact that the Hurwicz criterion takes only extreme payoffs into consideration (transitional values connected with a given decision are ignored). Additionally, the above rule does not examine the frequency of relatively high and low payoffs belonging to the set of all profits assigned to particular alternatives (see $[11,13,16])$. In the $\mathrm{H}+\mathrm{B}$ rule, in contradiction to the Hurwicz approach, all outcomes have an influence on the value of the final measure.

In the first step, the hybrid requires us to present the payoffs of each alternative as a non-increasing sequence $S q_{j}=\left(a_{1 j}, \ldots, a_{s j}, \ldots, a_{m j}\right)$ where $m$ still denotes the number of scenarios, $s$ is the number of the term and $a_{s, j} \geq a_{s+1, j}$ $(s=1,2, \ldots, m-1)$.

In the second step, it is recommended to calculate for each decision index $h b_{j}\left(h b_{j}^{p}, h b_{j}^{o}\right.$ or $h b_{j}^{0.5}$ depending on parameter $\left.\alpha\right)$. If $\alpha \in(0.5,1]$, calculate $h b_{j}^{p}$ (i.e. the index for pessimists) according to Equation (2). If $\alpha \in[0,0.5)$, compute $h b_{j}^{o}$ (the index for optimists) following formula (3). If $\alpha=0.5$, calculate $h b_{j}^{05}$ using Equation (4).

$$
\begin{gathered}
h b_{j}^{p}=\frac{\alpha_{p} \cdot a_{m j}+\beta_{p} \cdot \sum_{s=1}^{m-1} a_{s j}}{(m-1)\left(1-\alpha_{p}\right)+\alpha_{p}} \\
h b_{j}^{o}=\frac{\alpha_{o} \cdot \sum_{s=2}^{m} a_{s j}+\beta_{o} \cdot a_{1 j}}{(m-1) \cdot \alpha_{o}+1-\alpha_{o}} \\
h b_{j}^{0.5}=h b_{j}^{p}=h b_{j}^{o}=b_{j}=\frac{1}{m} \cdot \sum_{i=1}^{m} a_{i j}
\end{gathered}
$$

where $b_{j}$ denotes the Bayes criterion, i.e. the average of all payoffs.

The denominators in Equations (2) and (3) are introduced so that the final value of particular indices belong to the interval $\left[w_{j}, m_{j}\right]$, where $w_{j}$ and $m_{j}$ are the values of the Wald criterion and the maximax criterion respectively, i.e. the last $\left(a_{m j}\right)$ and the first $\left(a_{1 j}\right)$ term of $S q_{j .}$. Hence, these denominators are not crucial they can be omitted when preparing the ranking.

In the third and last step, one should choose the alternative fulfilling condition (5).

$$
h b_{j}^{*}=\max _{j}\left\{h b_{j}\right\}
$$


The assignment of such parameters $(\alpha$ and $\beta$ ) to particular payoffs, depending on the level of optimism, is justified in [13]. Briefly, the $\mathrm{H}+\mathrm{B}$ rule recommends for a pessimist an alternative with a relatively high payoff $a_{m j}$ or with quite frequent high payoffs. For an optimist, this procedure suggests an alternative with the highest payoff $a_{1 j}$, but its highest payoffs do not have to be frequent.

In contradiction to the Hurwicz rule, the $\mathrm{H}+\mathrm{B}$ approach recommends logic rakings for both symmetric and asymmetric distributions of payoffs. In the next section, we will attempt to modify the original Omega ratio by using the concept of the $\mathrm{H}+\mathrm{B}$ rule.

\section{Combining the Omega ratio and the $\mathrm{H}+\mathrm{B}$ rule as a new approach in decision making under uncertainty}

A possible procedure combining the Omega ratio with the hybrid of the Hurwicz and Bayes rules consists of the following steps:

1) Define the DM's point of reference $(r)$.

2) Transform initial outcomes $\left(a_{i j}\right)$ into relative outcomes $\left(a_{i j}^{r}\right)$ on the basis of the reference point:

$$
a_{i j}^{r}=a_{i j}-r \quad i=1, \ldots, m ; j=1, \ldots, n
$$

3) Define a non-increasing sequence of gains $S q(G)_{j}=\left(g_{1 j}, \ldots, g_{u j}, \ldots, g_{x j}\right)$ for each alternative, where $g_{u, j} \geq g_{u+1, j}(u=1,2, \ldots, x-1)$, and a nondecreasing sequence of losses $S q(L)_{j}=\left(l_{1 j}, \ldots, l_{w j}, \ldots, l_{z j}\right)$, where $l_{w, j} \leq l_{w+1, j}$ $(w=1,2, \ldots, z-1):$

$$
\begin{array}{rlrl}
a_{i j}^{r}>0 \Rightarrow a_{i j}^{r}=g_{u j} \in S q(G)_{j} & j=1, \ldots, n ; i=1, \ldots, m \\
a_{i j}^{r}<0 \Rightarrow\left|a_{i j}^{r}\right|=l_{w j} \in S q(L)_{j} & j=1, \ldots, n ; i=1, \ldots, m
\end{array}
$$

Notice that $0 \leq x+z \leq m$ ( $x$ - number of gains, $z$-number of losses).

4) Determine $\alpha$, i.e. the DM's coefficient of pessimism (as an individual measure of the attitude towards risk):

a) If $\alpha \in[0,0.5)$, then $\alpha=\alpha_{o}, \beta=\beta_{o}\left(\alpha_{o}\right.$ and $\beta_{o}$ are the optimist's coefficients).

b) If $\alpha \in(0.5,1]$, then $\alpha=\alpha_{p}, \beta=\beta_{p}$ ( $\alpha_{p}$ and $\beta_{p}$ are the pessimist's coefficients).

5) For each decision, compute numerator $N_{j}$ and denominator $D n_{j}$ according to the following equations:

a) If $1<x<m, 1 \leq z<m$ and $\alpha \in[0,0.5)$ :

$$
N_{j}=\beta_{o} \cdot g_{1 j}+\alpha_{o} \cdot \sum_{u=2}^{x} g_{u j}, \quad D n_{j}=\alpha_{o} \cdot \sum_{w=1}^{z} l_{w j} \quad j=1, \ldots, n
$$


b) If $x=1,1 \leq z<m$ and $\alpha \in[0,0.5)$ :

$$
\begin{array}{lrl}
N_{j}=\beta_{o} \cdot g_{1 j}, & D n_{j}=\alpha_{o} \cdot \sum_{w=1}^{z} l_{w j} & j=1, \ldots, n \\
\text { c) If } x=0,1 \leq z \leq m \text { and } \alpha \in[0,0.5): & \\
N_{j}=0, & D n_{j}=\beta_{o} \cdot l_{1 j}+\alpha_{o} \cdot \sum_{w=2}^{z} l_{w j} & j=1, \ldots, n
\end{array}
$$

d) If $1 \leq x \leq m, z=0$ and $\alpha \in[0,0.5)$ :

$$
N_{j}=\beta_{o} \cdot g_{1 j}+\alpha_{o} \cdot \sum_{u=2}^{x} g_{u j}, \quad D n_{j}=0 \quad j=1, \ldots, n
$$

e) If $1 \leq x<m, 1<z<m$ and $\alpha \in(0.5,1]$ :

$$
\begin{aligned}
& N_{j}=\beta_{p} \cdot \sum_{u=1}^{x} g_{u j}, \quad D n_{j}=\beta_{p} \cdot \sum_{w=1}^{z-1} l_{w j}+\alpha_{p} \cdot l_{z j} \quad j=1, \ldots, n \\
& \text { f) If } 1 \leq x<m, \quad z=1 \text { and } \alpha \in(0.5,1]:
\end{aligned}
$$

$$
N_{j}=\beta_{p} \cdot \sum_{u=1}^{x} g_{u j}, \quad D n_{j}=\alpha_{p} \cdot l_{1 j} \quad j=1, \ldots, n
$$

g) If $x=0,1 \leq z \leq m$ and $\alpha \in(0.5,1]$ :

$$
N_{j}=0, \quad D n_{j}=\beta_{p} \cdot \sum_{w=1}^{z-1} l_{w j}+\alpha_{p} \cdot l_{z j} \quad j=1, \ldots, n
$$

h) If $1 \leq x \leq m, z=0$ and $\alpha \in(0.5,1]$ :

$$
N_{j}=\beta_{p} \cdot \sum_{u=1}^{x-1} g_{u j}+\alpha_{p} \cdot g_{x j}, \quad D n_{j}=0 \quad j=1, \ldots, n
$$

i) If $\alpha=0.5$, one can use any formulas (see Equations (9)-(16)) depending on the value of $x$ and $z$. Regardless of the applied formula, $N_{j}$ is equal to the arithmetical mean of gains and $D n_{j}$ is the arithmetical mean of losses.

6) Divide all alternatives $D_{j}$ into three groups: (A) alternatives with a positive numerator and denominator, (B) alternatives with a positive numerator and a zero denominator, (C) alternatives with a zero numerator and a positive denominator:

$$
\begin{aligned}
& \left(N_{j}>0\right) \wedge\left(D n_{j}>0\right) \Rightarrow D_{j} \in A \\
& \left(N_{j}>0\right) \wedge\left(D n_{j}=0\right) \Rightarrow D_{j} \in B \\
& \left(N_{j}=0\right) \wedge\left(D n_{j}>0\right) \Rightarrow D_{j} \in C
\end{aligned}
$$

7) Find the best decision in each group separately (choose alternatives fulfilling Equations (20)-(22)) and determine $D$ - the set of the best decisions from each group. If $D$ is a singleton, stop (the best solution is found). Otherwise, go to step 8.

$$
\Omega(h b)_{j^{*}}^{A}=\max _{D_{j} \in A}\left\{\frac{N_{j}}{D n_{j}}\right\}
$$




$$
\begin{aligned}
& \Omega(h b)_{j^{*}}^{B}=\max _{D_{j} \in B}\left\{N_{j}\right\} \\
& \Omega(h b)_{j^{*}}^{C}=\min _{D_{j} \in C}\left\{D n_{j}\right\}
\end{aligned}
$$

8) Find the optimal decision by means of an additional criterion (Equation 23) used only for the decisions selected in step (7), i.e. for the decisions belonging to $D$ :

$$
\Omega(h b)_{j^{*}}=\max _{D_{j} \in D}\left\{N_{j}-D n_{j}\right\}
$$

If more than one alternative fulfills condition (23), it means that there is more than one optimal solution. If the sets $B$ and $C$ are empty, but more than one alternative satisfies condition (20), then the additional criterion (Equation 23) may facilitate the selection of one optimal solution.

\section{Illustration}

Let us illustrate an application of the Omega $(\mathrm{H}+\mathrm{B})$ ratio. In the analyzed example, the DM can select one of seven decisions. It is a fact that one out of five scenarios will occur in the future. Possible outcomes dependent on the chosen alternative and on the true event are given in Table 1. Tables 2-4 present relative outcomes (Equation 6), gains and losses (Equations 7-8) respectively, on the assumption that the reference point is equal to $r=9$ (steps 1-3). The sequences of losses contain more terms than do the sequences of gains due to the high level of $r$. Assume that the DM's coefficient of pessimism amounts to $\alpha=0.35$ (step 4). Hence, the DM is a moderate optimist. The first two rows of table 5 contain the values of the numerators and denominators (step 5). The numerators for D2, D4 and D7 are equal to zero because those decisions have no gains. In the third row of Table 5 , the alternatives have been assigned to an appropriate group (step 6): $\mathrm{A}=\{\mathrm{D} 1, \mathrm{D} 3, \mathrm{D} 5, \mathrm{D} 6\}, \mathrm{B}=\{\varnothing\}$, $\mathrm{C}=\{\mathrm{D} 2, \mathrm{D} 4, \mathrm{D} 7\}$. The fourth and fifth row present the Omega $(\mathrm{H}+\mathrm{B})$ ratio. As can be seen, D5 is the best decision within Group A, and D2 is the best decision among alternatives belonging to Group $C$ (step 7): $D=\{D 2, D 5\}$. Now let us compute the additional measure for the two winners (sixth row) - D5 is the optimal solution (step 8). 


\begin{tabular}{|c|c|c|c|c|c|c|c|}
\hline Scenarios $\backslash$ Decisions & D1 & D2 & D3 & D4 & D5 & D6 & D7 \\
\hline S1 & 4 & 7 & 3 & -6 & 0 & 16 & -4 \\
\hline S2 & 5 & 3 & 10 & 9 & -7 & -4 & 9 \\
\hline S3 & 12 & 8 & -3 & 4 & -8 & -3 & 0 \\
\hline S4 & -2 & 9 & -4 & 8 & 20 & 11 & 9 \\
\hline S5 & 4 & -2 & 13 & 9 & 15 & 3 & 8 \\
\hline
\end{tabular}

Table 1: Payoff matrix (example)

\begin{tabular}{|c|c|c|c|c|c|c|c|}
\hline Scenarios \Decisions & D1 & D2 & D3 & D4 & D5 & D6 & D7 \\
\hline S1 & -5 & -2 & -6 & -15 & -9 & 7 & -13 \\
\hline S2 & -4 & -6 & 1 & 0 & -16 & -13 & 0 \\
\hline S3 & 3 & -1 & -12 & -5 & -17 & -12 & -9 \\
\hline S4 & -11 & 0 & -13 & -1 & 11 & 2 & 0 \\
\hline S5 & -5 & -11 & 4 & 0 & 6 & -6 & -1 \\
\hline
\end{tabular}

Table 2: Relative payoff matrix, $r=9$ (example)

\begin{tabular}{|c|c|c|c|c|c|c|c|}
\hline$S_{j} \backslash D_{j}$ & D1 & D2 & D3 & D4 & D5 & D6 & D7 \\
\hline S1 & - & - & - & - & - & 7 & - \\
\hline S2 & - & - & 1 & - & - & - & - \\
\hline S3 & 3 & - & - & - & - & - & - \\
\hline S4 & - & - & - & - & 11 & 2 & - \\
\hline S5 & - & - & 4 & - & 6 & - & - \\
\hline$x$ & 1 & 0 & 2 & 0 & 2 & 2 & 0 \\
\hline$S q(G)_{j}$ & $(3)$ & - & $(4,1)$ & - & $(11,6)$ & $(7,2)$ & - \\
\hline
\end{tabular}

Table 3: Gain matrix, $r=9$ (example)

\begin{tabular}{|c|c|c|c|c|c|c|c|}
\hline$S_{j} \backslash D_{j}$ & $\mathrm{D} 1$ & $\mathrm{D} 2$ & $\mathrm{D} 3$ & $\mathrm{D} 4$ & $\mathrm{D} 5$ & $\mathrm{D} 6$ & $\mathrm{D} 7$ \\
\hline $\mathrm{S} 1$ & 5 & 2 & 6 & 15 & 9 & - & 13 \\
\hline $\mathrm{S} 2$ & 4 & 6 & - & - & 16 & 13 & - \\
\hline $\mathrm{S} 3$ & - & 1 & 12 & 5 & 17 & 12 & 9 \\
\hline $\mathrm{S} 4$ & 11 & - & 13 & 1 & - & - & - \\
\hline $\mathrm{S} 5$ & 5 & 11 & - & - & - & 6 & 1 \\
\hline$z$ & 4 & 4 & 3 & 3 & 3 & 3 & 3 \\
\hline$S q(L)_{j}$ & $(4,5,5,11)$ & $(1,2,6,11)$ & $(6,12,13)$ & $(1,5,15)$ & $(9,16,17)$ & $(6,12,13)$ & $(1,9,13)$ \\
\hline
\end{tabular}

Table 4: Loss matrix, $r=9$ (example)

\begin{tabular}{|c|c|c|c|c|c|c|c|}
\hline Decisions & D1 & D2 & D3 & D4 & D5 & D6 & D7 \\
\hline$N_{j}$ & 1.95 & 0.00 & 2.95 & 0.00 & 9.25 & 5.25 & 0.00 \\
\hline$D n_{j}$ & 8.75 & 7.30 & 10.85 & 7.65 & 14.70 & 10.85 & 8.35 \\
\hline Group & $\mathrm{A}$ & $\mathrm{C}$ & $\mathrm{A}$ & $\mathrm{C}$ & $\mathrm{A}$ & $\mathrm{A}$ & $\mathrm{C}$ \\
\hline$\Omega(h b)^{A}{ }_{j}=N_{j} / D n_{j}$ & 0.22 & - & 0.27 & - & $\mathbf{0 . 6 3}$ & 0.48 & - \\
\hline$\Omega(h b)^{C}=D n_{j}$ & - & $\mathbf{7 . 3 0}$ & - & 7.65 & - & - & 8.35 \\
\hline$\Omega(h b)_{j}$ & - & -7.30 & - & - & $\mathbf{- 5 . 4 5}$ & - & - \\
\hline
\end{tabular}

Table 5: Numerators, denominators and Omega $(H+B)$ ratios for particular decisions $(\alpha=0.35)$. 
Note that for a moderate pessimist (e.g. $\alpha=0.65$ ), the sets A, B, C and D are totally the same in this example, but the final optimal decision is D2. Thus, we see that the Omega $(\mathrm{H}+\mathrm{B})$ ratio recommends different strategies depending on the DM's risk aversion, which is certainly a valuable feature of the new approach. The fact that all outcomes concerning particular decisions have an impact on the suggested solution is also advantageous (compare with [16]).

\section{Conclusions}

Previous research has shown that the Omega ratio has been used in decision making under risk (DMUR) or decision making with partial information (DMPI). This paper presents how it can be used in decision making under uncertainty (DMUU). Thanks to a combination of the Omega ratio with the hybrid of the Hurwicz and Bayes rules, we obtain an index that takes into account all gains and losses (the Bayes rule takes into consideration all outcomes, that is, the frequency of good and bad results) and which, additionally, is adjusted to the decision maker's attitude towards risk (the Hurwicz rule is based on the coefficients of pessimism and optimism). Note that the last factor is not considered in the original version of the $\Omega$ ratio. However, in the author's opinion, DM's preferences should be taken into account in the case of uncertainty. They do have an impact on the final decision.

It is also worth emphasizing that, for decisions with zero numerators or denominators, the Omega $(\mathrm{H}+\mathrm{B})$ ratio incorporates principles proposed by Michalska [38]. As we observed in the above example, zero numerators and denominators may occur when a given decision has no gains or no losses, but this is not the only situation where an alternative does not belong to the set $\mathrm{A}$. The zero dividend or divisor in the fraction $N_{j} / D n_{j}$ also occurs when we deal with an extreme optimist $(\alpha=0.00)$ or a radical pessimist $(\alpha=1.00)$, even if the decision has both gains and losses!

Due to the existence of four criteria in the suggested Omega $(\mathrm{H}+\mathrm{B})$ rule (separate criteria for the sets A, B, C and D), this procedure is designed to select the optimal decision and, if possible, generate a ranking of the best decisions, i.e. a ranking of the winners from particular groups. As a matter of fact, a complete ranking of all alternatives can be obtained merely when (a) all of them belong to the same group or (b) the value of the Omega $(\mathrm{H}+\mathrm{B})$ ratio is the same for all decisions within the framework of particular groups.

The Omega $(\mathrm{H}+\mathrm{B})$ ratio is always a non-negative number, but the additional criterion $\left(N_{j}-D n_{j}\right)$ may be negative. The new measure, like the Omega ratio for DMUR, copes with not normally distributed return distributions. The significant advantage of the $\Omega(\mathrm{H}+\mathrm{B})$ rule is the possibility of comparing alternatives (strategies, projects) when the likelihood of particular scenarios is not known, or when the DM does not intend to use the available data. Future 
research could take into account the structure of the payoff matrix in constructing the previously mentioned measure, as the position of particular outcomes in the set of all payoffs connected with a decision seems to be important in the decision making process (compare with [17]).

\section{References}

[1] Bargman, D. (2012). Think on the Downside. Multifactor asset pricing models based on the downside risk and their performance relative to the CAPM, FF3F and Momentum. Msc Thesis, Supervisor: Tedongap, R., Stockholm School of Economics, Deparment of Finance. arc.hhs.se/download. aspx?MediumId=1752 [Accessed on 12 June 2014].

[2] Basili, M. (2006). A rational decision rule with extreme events. Risk Analysis, 26(7), 1721-1728. doi:10.1111/j.1539-6924.2006.00826.x.

[3] Basili, M., Chateauneuf, A., and Fontini, F. (2008). Precautionary principle as a rule of choice with optimism on windfall gains and pessimism on catastrophic losses. Ecological Economics, 67(3), 485-491. doi:10.1016/j.ecolecon.2007.12.030.

[4] Basili, M., and Chateauneuf, A. (2011). Extreme events and entropy: a multiple quantile utility model. International Journal of Approximate Reasoning, 52, 10951102. doi:10.1016/j.ijar.2011.05.005.

[5] Cannon, C. M., and Kmietowicz, Z. W. (1974). Decision theory and incomplete knowledge. Journal of Management Studies, 11(3), 224-232. doi:10.1111/j.14676486.1974.tb00695.x.

[6] Chronopoulos, M., De Reyck, B., and Siddiqui, A. (2011). Optimal investment under operational flexibility, risk aversion, and uncertainty. European Journal of Operational Research, 213, 221-237. doi:10.1016/j.ejor.2011.03.007.

[7] de Finetti, B. (1974). Theory of Probability. New York: Wiley.

[8] Ellsberg, D. (2001). Risk, Ambiguity and Decision. New York: Garland Publishing.

[9] Etner, J., Jeleva, M., and Tallon, J.-M. (2012). Decision theory under ambiguity. Journal of Economic Surveys. 26(2), 234-270. doi:10.1111/j.1467-6419.2010.00641.x.

[10] Gaspars, H. (2007). Alokacja zasobu w warunkach niepewności: modele decyzyjne i procedury obliczeniowe (Resource allocation under uncertainty: choice models and computational procedures). Badania Operacyjne i Decyzje (Operations research and decision), 17(1), 5-27.

[11] Gaspars-Wieloch, H. (2012). Ograniczona skuteczność metod optymalizacyjnych w rozwiązywaniu ekonomicznych problemów decyzyjnych (Limited efficiency of optimization methods in solving economic decision). Ekonomista 2012/3, 303-324.

[12] Gaspars-Wieloch, H. (2013). On a decision rule supported by a forecasting stage based on the decision maker's risk aversion. In: Zadnik Stirn, L., Zerovnik, J., Povh, J., Drobne, S. and Lisec, A. (Eds.). SOR'13 Proceedings, The $12^{\text {th }}$ International Symposium on Operational Research in Slovenia, September 25-27, 2013 (pp. 5359). Slovenian Society INFORMATIKA, Section for Operational Research.

[13] Gaspars-Wieloch, H. (2014a). Propozycja hybrydy reguł Hurwicza i Bayesa w podejmowaniu decyzji $\mathrm{w}$ warunkach niepewności (A hybrid of the Hurwicz and Bayes rules in decision making under uncertainty). In: Trzaskalik, T. (Ed.) 
Modelowanie preferencji a ryzyko 2014 (Preference Modeling and Risk 2014). Studia Ekonomiczne (Economic Studies). Zeszyty Naukowe Uniwersytetu Ekonomicznego w Katowicach (Scientific Papers of the University of Economics in Katowice), 178, 7492.

[14] Gaspars-Wieloch, H. (2014b). On a decision rule for mixed strategy searching under uncertainty on the basis of the coefficient of optimism. Procedia - Social and Behavioral Sciences. Elsevier, 110, 923-931. doi:10.1016/j.sbspro.2013.12.938.

[15] Gaspars-Wieloch, H. (2014c). On a decision rule supported by a forecasting stage based on the decision maker's coefficient of optimism. Central European Journal of Operations Research, Springer, doi:10.1007/s10100-014-0364-5.

[16] Gaspars-Wieloch, H. (2014d). Modifications of the Hurwicz's decision rules. Central European Journal Operations Research, Springer, 22(4), 779-794. doi:10.1007/s10100-013-0302-y.

[17] Gaspars-Wieloch, H. (2014e). Modifications of the maximin joy criterion for decision making under uncertainty. Quantitative Methods in Economics XV, 84-93.

[18] Ghirardato, P., Maccheroni, F., and Marinacci, M. (2004). Differentiating ambiguity and ambiguity attitude. Journal of Economic Theory, 118(2), 133-173. doi:10.1016/j.jet.2003.12.004.

[19] Gilboa, I. (2009). Theory of Decision Under Uncertainty. Cambridge University Press.

[20] Gilboa, I., and Schmeidler, D. (1989). Maxmin expected utility with non-unique prior. Journal of Mathematical Economics, 18(2), 141-153. doi:10.1016/03044068(89)90018-9.

[21] Groenewald, M.E., and Pretorius, P.D. (2011). Comparison of decision making under uncertainty investment strategies with the money market, Journal of Financial Studies and Research, doi: 10.5171/2011.373376.

[22] Guo, P. (2011). One-shot decision theory. IEEE Transactions on Systems, Man and Cybernetics, P. A 41(5), 917-926. doi:10.1109/tsmca.2010.2093891.

[23] Hayashi, T. (2006). Regret Aversion and Opportunity-Dependence. Austin: Mimeo, University of Texas.

[24] Hayashi, T. (2008). Regret aversion and opportunity dependence. Journal of Economic Theory, 139(1), 242-268. doi:10.1016/j.jet.2007.07.001.

[25] Hurwicz, L. (1952). A criterion for decision making under uncertainty. Technical Report, 355. Cowles Commission.

[26] Hurwicz, L. (1951). The generalized Bayes minimax principle: a criterion for decision making under uncertainty. Discussion Paper Statistics, 335. Cowles Commission.

[27] Kahneman, D., and Tversky, A. (1979). Prospect theory: an analysis of decision under risk. Econometrica, 47(2), 263-291. doi:10.2307/1914185.

[28] Kaplan, P. D., and Knowles, J. A. (2004). Kappa: a generalized downside riskadjusted performance measure. Journal of Performance Measurement, 8, 42-54.

[29] Kapsos, M., Christofides, N., and Rustem B. (2014). Worst-case robust Omega ratio. European Journal of Operational Research, 234(2), 499-507. doi:10.1016/j.ejor.2013.04.025.

[30] Kapsos, M., Zymler, S., Christofides, N., and Rustem, B. (2014). Optimizing the Omega ratio using linear programming. Journal of Computational Finance, 17, 4957. 
[31] Kazemi, H., Schneeweis, T., and Gupta, B. (2004). Omega as a performance measure. Journal of Performance Measurement, 8, 16-25.

[32] Kmietowicz, Z. W., and Pearman, A. D. (1984). Decision theory, linear partial information and statistical dominance. Omega, 12, 391-399. doi:10.1016/03050483(84)90075-6.

[33] Knight, F. H. (1921). Risk, Uncertainty, Profit. Boston MA: Hart. Schaffner and Marx, Houghton Mifflin Co.

[34] Kofler, E., and Menges, G. (1976). Entscheidungen Bei Unvollständiger Information. Springer Verlag.

[35] Kofler, E., and Zweifel, P. (1993). One-shot decisions under linear partial information. Theory and Decision, 34, 1-20. doi:10.1007/bf01076102.

[36] Marinacci, M. (2002). Probabilistic sophistication and multiple priors. Econometrica, 70(2), 755-764. doi:10.1111/1468-0262.00303.

[37] Mausser, H., Saunders, D., and Seco, L. (2006). Optimizing Omega. Risk, 88-92.

[38] Michalska, E. (2014). Zastosowanie wskaźnika Omega w podejmowaniu decyzji przy niepełnej informacji liniowej (Application of the Omega ratio in decision making with partial information). In: Gajda, J. B. (Ed.) Metody i zastosowania badań operacyjnych 2013 (Methods and Applications of Operations Research). Łódź: Wydawnictwo Uniwersytetu Łódzkiego (in print).

[39] Officer, R. R., and Anderson, J. R. (1968). Risk, uncertainty and farm management decisions. Review of Marketing and Agricultural Economics, 36(01), 3-19.

[40] Pazek, K., and Rozman, C. (2009). Decision making under conditions of uncertainty in agriculture: a case study of oil crops. Poljoprivreda (Osijek) 15(1), 45-50.

[41] Piasecki, K. (1990). Decyzje i Wiarygodne Prognozy (Decisions and reliable forecasts). Poznań: Akademia Ekonomiczna w Poznaniu (Poznań: Academy of Economics in Poznań).

[42] Pomerol J.C. (2001). Scenario development and practical decision making under uncertainty. Decision Support Systems 31(2), 197-204. doi:10.1016/s01679236(00)00131-7.

[43] Puppe, C., and Schlag, K. (2009). Choice under complete uncertainty when outcome spaces are state dependent. Theory and Decision 66, 1-16. doi:10.1007/s11238-0079082-y.

[44] Render, B., Stair, R. M., and Hanna, M. E. (2006). Quantitative Analysis for Management. New Jersey: Pearson Prentice Hall, Upper Saddle River.

[45] Savage, L. (1961). The foundations of statistics reconsidered. In: Studies in Subjective Probability (pp. 173-188). New York: Wiley.

[46] Schmeidler, D. (1986). Integral representation without additivity. Proceedings of the American Mathematical Society, 97(2), 255-261. doi:10.1090/s0002-9939-19860835875-8.

[47] Shadwick, W., and Keating, C. (2002a). A Universal Performance Measure. Working Paper. London: The Finance Development Centre.

[48] Shadwick, W., and Keating, C. (2002b). A universal performance measure. Journal of Performance Measurement, 59-84.

[49] Sharpe, W. F. (1966). Mutual fund performance. Journal of Business, 39 (S1), 119138. 
[50] Sharpe, W. F. (1994). The Sharpe Ratio. Journal of Portfolio Management, 21(1), $49-58$.

[51] Sikora, W. (Ed.) (2008). Badania Operacyjne (Operations Research). Warszawa: Polskie Wydawnictwo Ekonomiczne (Warsaw: Polish Economic Publishing House).

[52] Trzaskalik, T. (2008). Wprowadzenie Do Badań Operacyjnych z Komputerem (Introduction to operations research with a computer) (2nd ed.). Warszawa: Polskie Wydawnictwo Ekonomiczne (Warsaw: Polish Economic Publishing House).

[53] Tversky, A., and Kahneman, D. (1992). Advances in prospect theory: cumulative representation of uncertainty. Journal of Risk and Uncertainty, 5(4), 297-323. doi: $10.1007 /$ bf00122574.

[54] von Neumann, J., and Morgenstern, O. (1944). Theory of Games and Economic Behavior. Princeton University Press.

[55] Wald, A. (1950). Statistical Decision Functions. New York: Wiley.

[56] Weber, M. (1987). Decision making with incomplete information. European Journal of Operational Research, 28, 44-57. 